\title{
PENERAPAN METODE MFEP (MULTIFACTOR EVALUATION PROCESS) DALAM PENGAMBILAN KEPUTUSAN PEMILIHAN BIBIT KELAPA SAWIT TERBAIK
}

\author{
Muhammad Ikhlas ${ }^{1}$ \\ Fakultas Ilmu Komputer, Universitas Putra Indonesia YPTK Padang, Indonesia ${ }^{1}$ \\ email: mhdikhlas@upiyptk.ac.id
}

\begin{abstract}
Abstrak; Dalam menghasilkan kelapa sawit yang berkualitas, tentu diawali dengan pemilihan bibit kelapa sawit yang terbaik yang diperoleh berdasarkan kriteria yang ada. Kriteria yang diperlukan dalam mencari bibit terbaik dimulai dengan pembenihan, perkecambahan (pertumbuhan tunas kecil) dan pemilihan bibit sawit siap tanam. Berdasarkan kandungan minyak, ketebalan daging buah dan tempurung kelapa sawit dibedakan menjadi tiga varietas Dura, Pisifera, dan Tenera. Metode Multifactor Evaluation Process (MFEP) merupakan salah satu metode yang dapat digunakan dalam sistem pendukung keputusan. Dengan menggunakan metode MFEP setiap kriteria yang telah ditentukan diberikan bobot (weighting) sesuai dengan kebutuhannya. Kemudian setiap alternatif dievaluasi berdasarkan faktor-faktor pertimbangan tersebut. Alternatif dengan nilai tertinggi merupakan solusi dalam memilih bibit sawit terbaik. Metode MFEP dalam pengambilan keputusan pemilihan bibit kelapa sawit ini dikembangan menggunakan bahasa pemrograman Visual Basic 2010 dan database MySQL. Sehingga aplikasi dapat digunakan untuk membantu petani atau perusahaan dalam mengambil keputusan pemilihan bibit kelapa sawit terbaik.
\end{abstract}

Kata kunci: Sistem Pendukung Keputusan, Bibit Kelapa Sawit, MFEP, Visual Basic, Database

Abstract; In producing quality palm oil, of course it starts with the selection of the best oil palm seeds that are obtained based on existing criteria. The criteria needed in finding the best seeds start with seeding, germination (small shoot growth) and selection of ready-to-plant palm seedlings. Based on the oil content, the thickness of the fruit flesh and shell of oil palm is divided into three varieties of Dura, Pisifera, and Tenera. The Multifactor Evaluation Process (MFEP) method is one method that can be used in decision support systems. Using the MFEP method, each predetermined criteria is given weighting according to their needs. Then each alternative is evaluated based on these consideration factors. The alternative with the highest value is the solution in choosing the best palm seeds. The MFEP method in making decisions on the selection of oil palm seeds was developed using the Visual Basic 2010 programming language and MySQL database. So that the application can be used to help farmers or companies in making decisions regarding the selection of the best oil palm seeds.

Keywords: Decision Support Systems, Palm Oil Seeds, MFEP, Visual Basic, Database

\section{PENDAHULUAN}

Hadirnya teknologi informasi mengharuskan setiap individu, organisasi atau perusahanan mengikuti perkembangannya, karena setiap waktu kebutuhan akan informasi semakin meningkat dan berkembangan. Pemanfaatan teknologi informasi yang tepat akan menghasilkan informasi yang cepat, tepat dan akurat. Tidak terkecuali dalam memilih bibit kepala sawit yang terbaik pada CV Fajar. Bibit sawit terbaik akan sangat berpengaruh pada penjualan dan minat para pembeli dipasaran. Proses penyeleksian bibit sawit terbaik yang nantinya akan mendapatkan bibit sawit yang berkualitas tentu bukan hal yang mudah, diperlukan penyeleksian dalam pemilihan bibit sawit terbaik yang mampu nantinya membawa keuntungan. Keputusan yang diambil diharapkan lebih objektif agar kualitas yang diperoleh sesuai dengan harapan. Untuk mencapai hal tersebut maka 
diperlukan sistem pendukung keputusan dengan menggunakan metode MFEP (Multifactor Evalution Process).

Sistem pendukung keputusan dijadikan sebagai alternatif aplikasi sistem yang membantu dalam mengambil keputusan untuk pemilihan bibit sawit. Dalam pengambilan keputusan, SPK memanfaatkan data dan model untuk menyelesaikan masalah-masalah yang tak terstruktur. Dalam metode MFEP memerlukan beberapa kriteria yang nantinya akan diberikan bobot (weighting) yang sesuai dan kemudian alternatif setiap setiap kasus dievaluasi berdasarkan faktorfaktor pertimbangan tersebut. Sehingga didapatkan solusi terbaik dari setiap kasus ujinya.

\section{METODE PENELITIAN}

Penelitian ini disusun berdasarkan kerangka kerja atau metodologi mulai dari studi literatur, pengumpulan data, analisa sistem, pengembangan sistem dan implementasi sistem.

1. Studi Literatur

Penulis mencari dan mempelajari teori yang relefan dengan kasus dan menggunakannya sebagai referensi dalam penelitian.

2. Pengumpulan Data

Pengumpulan data dilakukan guna mengetahui faktor dan alternatif apa saja yang nantikan digunakan dalam membuat sistem.

3. Analisis Sistem

Setelah data dikumpulkan maka dilakukan analisis terhadap sistem sehingga dapat ditemukan solusi penyelesaian masalah. Dalam analisa sistem penulis menggunakan metode perancangan terstruktur dengan alat bantu yang digunakan adalah Data Flow Diagram (DFD) dan metode MFEP (Multifactor Evalution Process).

4. Pengembangan Sistem

Sistem yang telah dianalisa dan dirancangan kemudian dilakukan pengembangan dengan menggunakan bahasa pemrograman Visual Basic 2010 dan Database MySQL

5. Implementasi Sistem

Implementasi dilalukan agar diperoleh hasil yang diharapkan dengan hasil yang sebenarnya. Sehingga sistem dapat diterapkan di perusahaan.

\section{HASIL DAN PEMBAHASAN}

\section{A. Desain Sistem}

1. Data Flow Diagram (DFD)

Pada CV. Fajar terdapat 3 entitas sistem yaitu pimpinan, petani dan admin. Adapun diagram arus data yang akan menggambarkan alir kerja logis dari sistem yang dikembangkan adalah sebagai berikut:

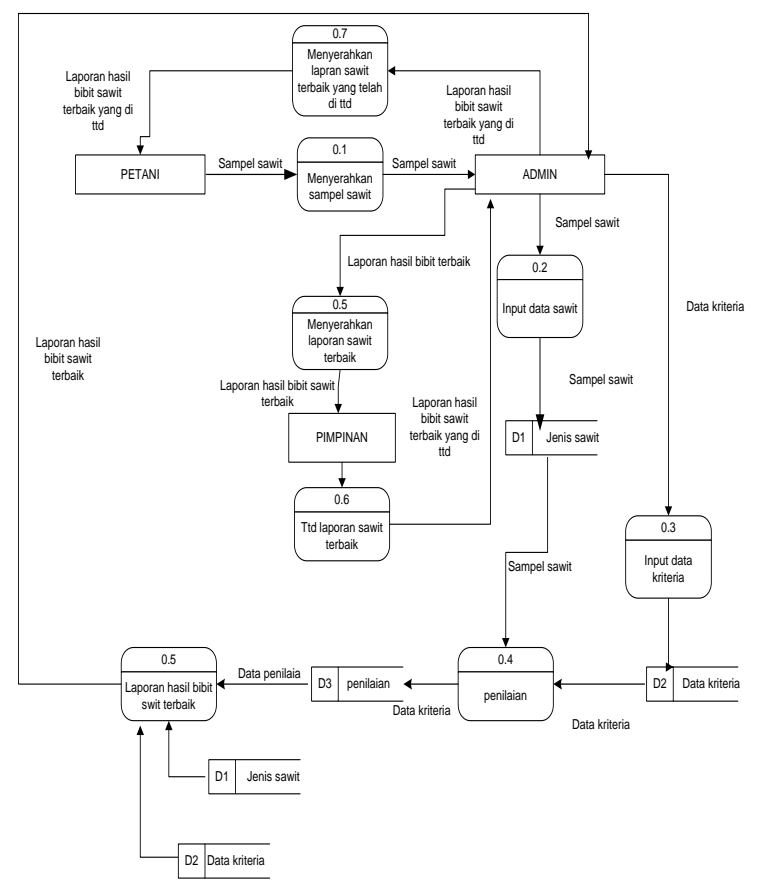

Gambar 1. Data Flow Diagram (DFD)

Level 0

\section{Entity Relationship Diagram (ERD)}

Hubungan atau relasi antar file yang terdapat dalam sistem ini digambarkan dalam bentuk ERD sebagai berikut : 


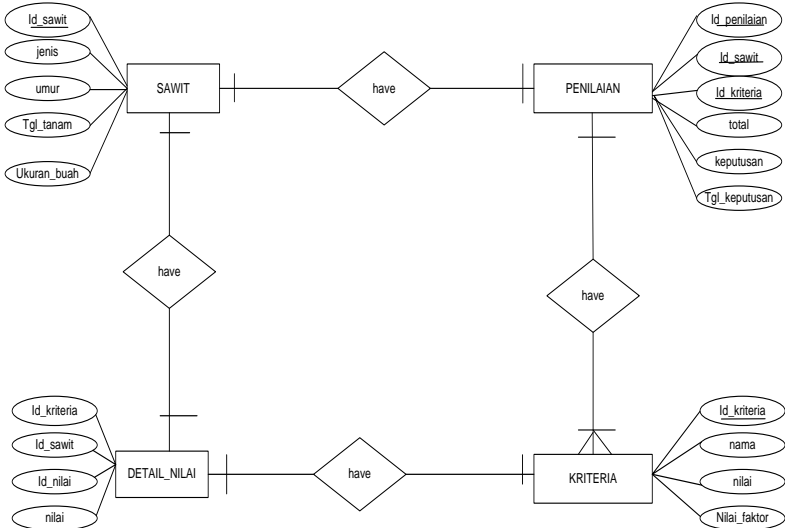

Gambar 2. Entity Relationship Diagram (ERD)

\section{B. Metode MFEP}

1. Nilai Bobot Faktor Adapun nilai bobot masing faktorfaktor penilaian adalah sebagai berikut:

Tabel 1. Nilai Bobot Faktor

\begin{tabular}{|l|c|}
\hline Faktor & Bobot \\
\hline Pembenihan & $55 \%$ \\
\hline Perkecambahan & $35 \%$ \\
\hline Pemilihan Bibit & $20 \%$ \\
\hline
\end{tabular}

2. Evaluasi Faktor

Adapun evaluasi faktor adalah sebagai berikut :

Tabel 2. Evaluasi Faktor

\begin{tabular}{|l|l|l|l|}
\hline \multicolumn{1}{|c|}{ Faktor } & $\begin{array}{l}\text { Verietas } \\
\text { dura }\end{array}$ & $\begin{array}{l}\text { Verietas } \\
\text { Pisifera }\end{array}$ & $\begin{array}{l}\text { Verietas } \\
\text { Tenera }\end{array}$ \\
\hline Pembenihan & $80 \%$ & $70 \%$ & $60 \%$ \\
\hline $\begin{array}{l}\text { Perkecam- } \\
\text { bahan }\end{array}$ & $90 \%$ & $80 \%$ & $90 \%$ \\
\hline $\begin{array}{l}\text { Pemilihan } \\
\text { bibit }\end{array}$ & $20 \%$ & $10 \%$ & $0 \%$ \\
\hline
\end{tabular}

\section{Evaluasi Bibit : Varietas Dura}

Tabel 3. Evaluasi Bibit : Varietas Dura

\begin{tabular}{|l|l|l|l|l|}
\hline Faktor & $\begin{array}{l}\text { Bobot } \\
\text { Faktor }\end{array}$ & $\begin{array}{l}\text { Evaluasi } \\
\text { Faktor }\end{array}$ & $\begin{array}{l}\text { Bobot } \\
\text { Evalua- } \\
\text { si }\end{array}$ \\
\hline $\begin{array}{l}\text { Pembe- } \\
\text { nihan }\end{array}$ & 0,55 & $\mathrm{X}$ & $80 \%$ & $2,8 \%$ \\
\hline $\begin{array}{l}\text { Perke- } \\
\text { cambahan }\end{array}$ & 0.35 & $\mathrm{X}$ & $90 \%$ & $4,95 \%$ \\
\hline $\begin{array}{l}\text { Pemelih- } \\
\text { anbibit }\end{array}$ & 0,20 & $\mathrm{X}$ & $20 \%$ & $0,20 \%$ \\
\hline Total & 1 & & & $7,95 \%$ \\
\hline
\end{tabular}

\section{Evaluasi Bibit : Varietas Pisifera}

Tabel 4. Evaluasi Bibit: Varietas Pisifera

\begin{tabular}{|l|l|l|l|l|}
\hline Faktor & $\begin{array}{l}\text { Bobot } \\
\text { Faktor }\end{array}$ & $\begin{array}{l}\text { Evaluasi } \\
\text { Faktor }\end{array}$ & $\begin{array}{l}\text { Bobot } \\
\text { Evalu- } \\
\text { asi }\end{array}$ \\
\hline $\begin{array}{l}\text { Pembe- } \\
\text { nihan }\end{array}$ & 0,55 & $\mathrm{X}$ & $70 \%$ & $2,45 \%$ \\
\hline $\begin{array}{l}\text { Perke- } \\
\text { cambahan }\end{array}$ & 0.35 & $\mathrm{X}$ & $80 \%$ & $4,4 \%$ \\
\hline $\begin{array}{l}\text { Pemilih-an } \\
\text { bibit }\end{array}$ & 0,20 & $\mathrm{X}$ & $10 \%$ & $0,1 \%$ \\
\hline Total & 1 & & & $6.95 \%$ \\
\hline
\end{tabular}

\section{Evaluasi Bibit : Varietas Tenera}

Tabel 5. Evaluasi Bibit : Varietas Tenera

\begin{tabular}{|l|l|l|l|l|}
\hline Faktor & $\begin{array}{l}\text { Bobot } \\
\text { Faktor }\end{array}$ & $\begin{array}{l}\text { Evaluasi } \\
\text { Faktor }\end{array}$ & $\begin{array}{l}\text { Bobot } \\
\text { Evalu- } \\
\text { asi }\end{array}$ \\
\hline $\begin{array}{l}\text { Pembe- } \\
\text { nihan }\end{array}$ & 0,55 & $\mathrm{X}$ & $60 \%$ & $2,1 \%$ \\
\hline $\begin{array}{l}\text { Perke- } \\
\text { cambaha } \\
\mathrm{n}\end{array}$ & 0.35 & $\mathrm{X}$ & $90 \%$ & $4,95 \%$ \\
\hline $\begin{array}{l}\text { Pemiliha } \\
\mathrm{n} \text { bibit }\end{array}$ & 0,20 & $\mathrm{X}$ & $0 \%$ & $0 \%$ \\
\hline Total & 1 & & & $7,05 \%$ \\
\hline
\end{tabular}

6. Hasil Keputusan

Hasil keputusan apabila rata-rata MFEP

$>7.00$

Tabel 6. Hasil Keputusan MFEP > 7.00

\begin{tabular}{|c|c|c|}
\hline Faktor & $\begin{array}{c}\text { Rata-rata } \\
\text { MFEP }\end{array}$ & Keterangan \\
\hline $\begin{array}{c}\text { Viretas } \\
\text { dura }\end{array}$ & $7.95 \%$ & Layak Tanam \\
\hline $\begin{array}{c}\text { Vireatas } \\
\text { Pisifera }\end{array}$ & $7.05 \%$ & Layak Tanam \\
\hline $\begin{array}{c}\text { Vireatas } \\
\text { Tenera }\end{array}$ & $6.95 \%$ & TIDAK Layak \\
\hline
\end{tabular}

\section{Implementasi Sistem}

1. Form Input Data Jenis Sawit

Form input data jenis sawit digunakan untuk memasukkan data jenis sawit yang akan dinilai. 


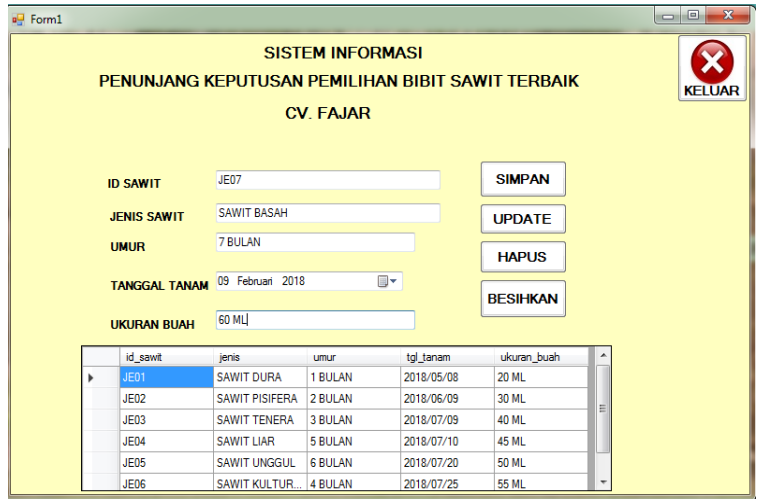

Gambar 3. Form Input Data Jenis Sawit

2. Form Input Nilai Kriteria

Form input nilai kriteria digunakan untuk memasukkan nilai kriteria.

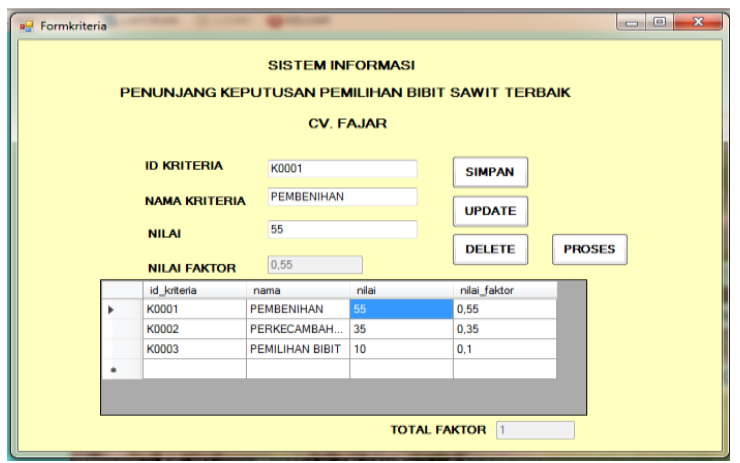

Gambar 4. Form Input Kriteria

3. Form Input Data Detail Nilai

Form input data detail nilai digunakan untuk memasukkan detail nilai setiap varietas bibit sawit yang akan dievaluasi.

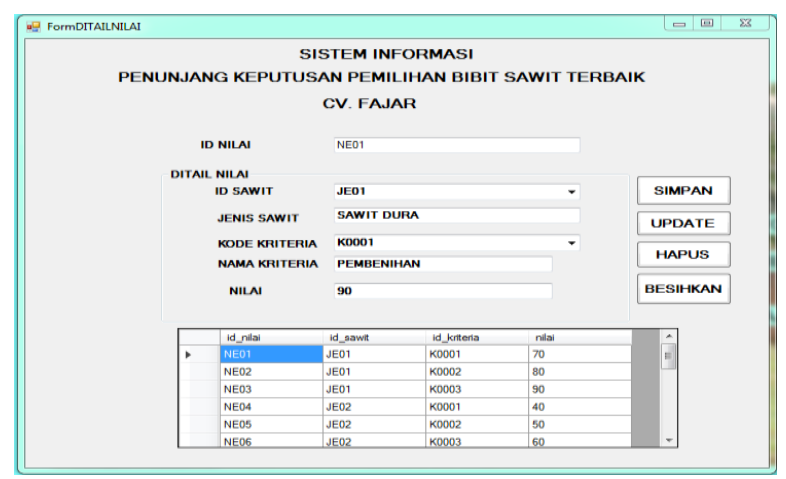

Gambar 5. Form Input Data Detail Nilai

4. Laporan Keputusan

Berikut adalah laporan hasil dari keputusan berdasarkan evaluasi setiap alternatif yang diberikan.

\begin{tabular}{|c|c|c|c|c|c|c|c|c|}
\hline \multicolumn{9}{|c|}{$\begin{array}{l}\text { LAPORAN HASL KEPUUUSAN } \\
\text { PEMIUHAN BIIT SAUT TEREAIK } \\
\text { CV. FANAR }\end{array}$} \\
\hline 10 & DSAUT & JELS & UMUR & TAIGGAL TANAM & UKURAN BUAH & ID PENIALAN & TOTAL & KEPUTUSAN \\
\hline 1 & JE01 & SAVIT DURA & 1BUAN & 201805008 & $20 \mathrm{ML}$ & PE01 & 75,50 & LAYAK TANAM \\
\hline 2 & JE15 & SAMT UNGGULl. & 66ULN & 20180720 & $50 \mathrm{ML}$ & PE015 & 70,50 & LAYAK TANAM \\
\hline 3 & JE06 & SAMT KUTRR, JAPN & 4BULN & 20180725 & $55 \mathrm{ML}$ & PE06 & 65,00 & IDAK LAYAK TANAU \\
\hline 4 & JEO3 & SAVIT TEVIERA & 3BUAN & 20180709 & 40 ML & PEO3 & 58,50 & IDAK LAYAK TANAM \\
\hline 5 & JEQ2 & SAMT PSEFERA & 2BUAN & 20180009 & $30 \mathrm{ML}$ & PEO2 & 4550 & IDAK LAYAK TALALA \\
\hline 6 & JEM & SAMTILAR & 5BUAN & 201807110 & $45 \mathrm{ML}$ & PE04 & 25,50 & TDAK LAYAK TAVAMII \\
\hline
\end{tabular}

Gambar 6. Laporan Keputusan

\section{KESIMPULAN}

Adapun kesimpulan yang diperoleh dari hasil penelitian ini adalah :

1. Penggunaan metode Multifactor Evaluation Process (MFEP) pada sistem yang dapat membantu petani dalam melakukan penyeleksian dalam pemilihan bibit sawit terbaik yang akan dipilih nantinya dalam pemilihan sawit yang siap ditanam.

2. Sistem ini diharapkan meminimalisir terjadinya kesalahan dalam pemilihan bibit sawit, sehingga tidak merugikan petani maupun perusahaan.

\section{DAFTAR PUSTAKA}

A.S, Rosa Dan M. Shalahudin. 2013. "Rekayasa Perangkat Lunak: Terstruktur dan Berorientasi Objek". Bandung : Informatika

Afrianty, Iis dan Revi Umbara. "Sistem Pendukung Keputusan (SPK) Menetukan Kelayakan Calon Penerima Zakat (MFEP)”. SNTIKI 8. UIN Suska Riau, Indonesia Pekanbaru . ISSN : 2085-9902

Dahria, Muhamad, dkk. "Pendukung Keputusan Penerimaan Calon POLRI Baru Di POLDA Kota Medan Menggunakan Metode MFEP”. Jurnal SAINTIKOM. STMIK Triguna Dharma Medan. Vol. 13, No. 2,ISSN : 1978-6603 
Kadir,Abdul. 2014. "Pengenenalan Sistem Informasi Edisi Revisi”. Yogyakarta: Andi

Khair, Hadriman, Darmawati J.S. dan Romi Saputra Sinaga." Uji Pertumbuhan Bibit Kelapa Sawit Dura Dan Varietas Unggul Dxp Simalungun ( Elaeis Guinensis Jacg) Terhadap Pupuk Organik CairDi Main Nursery”. Jurnal Agrium, Universitas Muhammadiyah Sumatera Utara. April 2014 Vol. 18, No. 3 ISSN: 0852-1077

Sutabri, Tata 2012. "Analisis Sistem Informasi”. Yogyakarta: Andi

Suyanto, Sigit.2012. "Visual Basic 2010 Programming”. Yogjakarta: Andi

Turaina Rifa Dkk. "SPK Dalam Pemilihan Siswa Kelas Unggul Menggunkan Metode MFEP Di SMPN 2 Solok". Jurnal Edik Informatika STKIP PGRI Sumbar.Vol 3. No. 2(125-135), ISSN : 2407-0491E-ISSN : 2541-3716

Turban, Efraim dan Dwi Prabanti. 2005. "Decision Support Systems and Intelligent Systems ( Sistem Pendukung Keputusan dan Sistem Cerdas )'”. Yogyakarta: Andi 